\title{
Publication Delay in the Korean Journal of $\quad$ Editorial Family Medicine
}

\section{Soo Young Kim}

Department of Family Medicine, Kangdong Sacred Heart Hospital, Hallym University College of Medicine, Seoul, Korea

Although much improved, the time between a manuscript's submission for publication and its release still somewhat long for the Korean Journal of family medicine (KJFM). The causes of this time lag may be various in nature. Delay of author's response after peer review, delayed answer of reviewers, or delayed assignment of peer reviewers may be among the main reasons.

Such publication delays may result in inflation of journal impact factors, ${ }^{1)}$ or may cause publication bias. ${ }^{2)}$ Therefore, efforts must be made to reduce such time lag for publication.

Adherence by the authors to several principles may prevent these delays. First, the conclusion must be carefully written. If the case is for amendment of manuscripts, the main reason for amendment may be regarding the conclusion. The conclusion must be based on the results pertaining to the research hypothesis. In many cases, the conclusion may contain only for the implication of results. In that case, it must be sent to the authors. Second, information for authors must be emphasized again. Many manuscripts are still not kept properly for information for authors. This may be the main reason for author amendments.

From the perspective of reviewers, quick and proper judgment in rejecting or amending must be made. It may happen that although the decision was modification of manuscripts, but the actual contents of review was close to reject of manuscripts, In addition the first review must be comprehensive, therefore not to point out in the second review the thing that was not pointed in the first review. This may be the reason for time lag.
Peer review and manuscript management in KJFM also need to be addressed. In addition, rejection without a review system, review training programs, a guide for reviewers, seeking to ways to compensate reviewers, or ways to develop and maintain reviewer loyalty should be prepared ${ }^{3)}$ by the editor and president of the Korean Academy of Family Medicine.

\section{CONFLICT OF INTEREST}

No potential conflict of interest relevant to this article was reported.

\section{REFERENCES}

1. Tort $\mathrm{AB}$, Targino $\mathrm{ZH}$, Amaral OB. Rising publication delays inflate journal impact factors. PLoS One 2012; 7:e53374.

2. Cochrane Bias Methods Group. Addressing reporting biases. In: Higgins JP, Green S, editors. Cochrane handbook for systematic reviews of interventions: version 5.0.0 [Internet]. Chichester: Wiley-Blackwell; 2008 [cited 2013 Sep 10]. Available from: http://www.cochrane-handbook.org.

3. Hames I. Peer review and manuscript management in scientific journals: guidelines for good practice. Oxford: Blackwell publishing; 2007. 